\title{
Bilan de la mission franco-albanaise à Sarda, 2017
}

\section{Etleva Nallbani, Véronique Gallien et Helidon Sokoli}

\section{(2) OpenEdition \\ Journals}

\section{Édition électronique}

URL : http://journals.openedition.org/cefr/2531

DOI : $10.4000 /$ cefr.2531

ISSN : 2282-5703

Éditeur

École française de Rome

Référence électronique

Etleva Nallbani, Véronique Gallien et Helidon Sokoli, « Bilan de la mission franco-albanaise à Sarda, 2017 », Chronique des activités archéologiques de l'École française de Rome [En ligne], Balkans, mis en ligne le 12 février 2019, consulté le 14 novembre 2019. URL : http://journals.openedition.org/cefr/2531

Ce document a été généré automatiquement le 14 novembre 2019.

(c) École française de Rome 


\title{
Bilan de la mission franco-albanaise à Sarda, 2017
}

\author{
Etleva Nallbani, Véronique Gallien et Helidon Sokoli
}

\section{NOTE DE L'AUTEUR}

L'équipe archéologique était composée par Etleva Nallbani, Véronique Gallien, Mathilde Ferrrari, Maël Julien, Alexandre Léger, Helidon Sokoli, Elvana Metalla, Ulsi Tota, et Ded Margjoni. Le programme de l'enregistrement photogrammétrique a été réalisé par Mathilde Ferrari (INRAP), la topographie par Alexandre Leger, Bledar Sina et Eduart Blloshmi (ces deux derniers de l'université de Tirana, sont intervenus ponctuellement pour positionner le site dans le système de cordonnées nationales géoréférencées). L'essentiel de la logistique de l'opération a été géré par la Mission archéologique franco-albanaise de « la Vallée du Drin ». La logistique a bénéficié de deux structures importantes situées à Komani : l'une hôtelière, la " Villa française », et l'autre de restauration, « chez Kastriot ».

1 Dans le cadre de la mission archéologique de « la Vallée du Drin » 2017, cette première campagne programmée s'est déroulée du 1 au 29 juillet, sur terrain, sur le site de Sarda (l'évêché médiéval sur l'île de Shurdhah). Située à une dizaine de kilomètres à l'est de Shkodra, l'île de Shurdhah, d'une superficie de 4,6 ha, résulte d'une montée des eaux du Drin due à la construction du barrage hydroélectrique de Koman dans les années 1970-1980. Elle conserve les ruines d'une ville médiévale quasi entière, protégée par deux murailles concentriques qui divisent la cité en ville basse et en ville haute. Les eaux du lac du barrage ont inondé les quartiers bas, à l'ouest et les quartiers suburbains, dont la nécropole avec deux églises, identifiées extra-muros, dans les années $1970^{1}$.

2 Rappelons que deux brèves missions de repérage (nettoyages et inventaires des structures anciennement fouillées) ont été initiées en 2015-2016. Le dernier défrichement important de lî̂le, délaissée depuis les dernières fouilles de type 
sauvetage menées lors de la création des barrages hydroélectriques dans les années 1970, a eu lieu en mai 2016. Il a été accompagné des premiers relevés topographiques de l'enceinte de la ville, dite haute, et d'une couverture de photos aériennes géoréférencées (fig. 1) ${ }^{2}$. La nouvelle phase de recherche programmée qui a démarré en 2017 a essentiellement porté sur la poursuite des défrichements, le relevé topographique de la cité, l'enregistrement photogrammétrique d'un certain nombre de bâtiments en élévation et sur le dégagement d'un nouveau secteur dans la ville haute. Ce dernier, situé sur le point haut de la cité médiévale, était principalement occupé par une église, repérée lors des fouilles anciennes.

Fig. 1 -Modèle 3D de l'ensemble du site de Sadra.

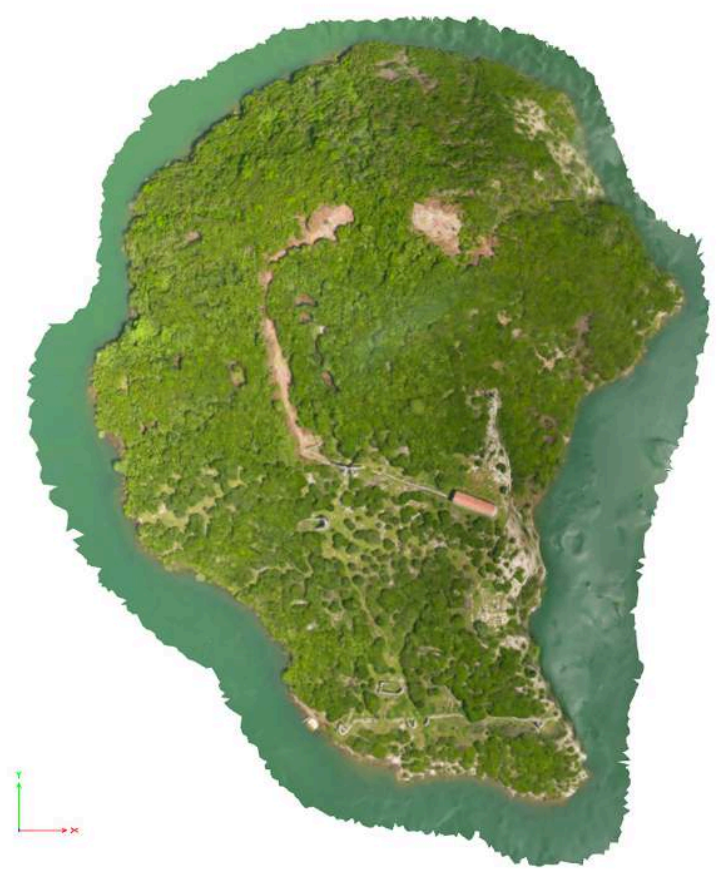

M. Pilz et M. Ferrari.

3 La forteresse, fondée probablement au IV ${ }^{\mathrm{e}}$ siècle, a bénéficié d'un fort développement urbain au Moyen Âge, devenant un centre épiscopal au XI ${ }^{e}$ siècle et recevant en cette occasion une deuxième enceinte ${ }^{3}$. Sarda est le siège de l'archevêque du diocèse de Pulatium Minor au XII ${ }^{\mathrm{e}}$ siècle et dépend de l'archevêché latin de Antibari ${ }^{4}$. La ville a connu son essor aux $\mathrm{XI}^{\mathrm{e}}$-XIII ${ }^{\mathrm{e}}$ siècles pour décliner au XIV ${ }^{\mathrm{e}}$ siècle, avec le transfert de l'évêché à Sapa. Les deux siècles suivants, Sarda est devenue une agglomération sans importance, avec un habitat dispersé. Elle a été définitivement abandonnée à la fin du $\mathrm{XV}^{\mathrm{e}}$ siècle, lors de l'invasion ottomane. Laissée à l'abandon depuis, la construction du barrage hydroélectrique de Koman des années 1980 a complètement isolé le site; l'accès se fait aujourd'hui uniquement en barque.

4 La mission de terrain 2017 du site archéologique de Sarda a commencé une importante campagne de numérisation des vestiges par photogrammétrie ; elle s'étendra à terme à l'ensemble du site. Cette démarche s'inscrit dans une volonté de poursuivre l'étude du 
bâti, abordée par les fouilles, en s'appuyant sur un premier modèle 3D du site fait au drone (2016).

5 Six édifices ont été modélisés : quatre églises reparties à l'intérieur des deux enceintes (fig. 2), la majorité de l'enceinte de la ville haute avec sa porte principale d'entrée à la ville (fig. 3). Pour chacun de ces édifices, dont les modèles 3D ont été géoréférencés, il a été possible d'extraire des ortho-images en plan et en élévation ainsi que des coupes. Ces documents vont pouvoir être utilisés dans l'étude du bâti, dans l'analyse du phasage chronologique ainsi que pour l'élaboration des plans des zones fouillées cette année.

Fig. 2 - Ortho-image en plan de l'église au dallage.

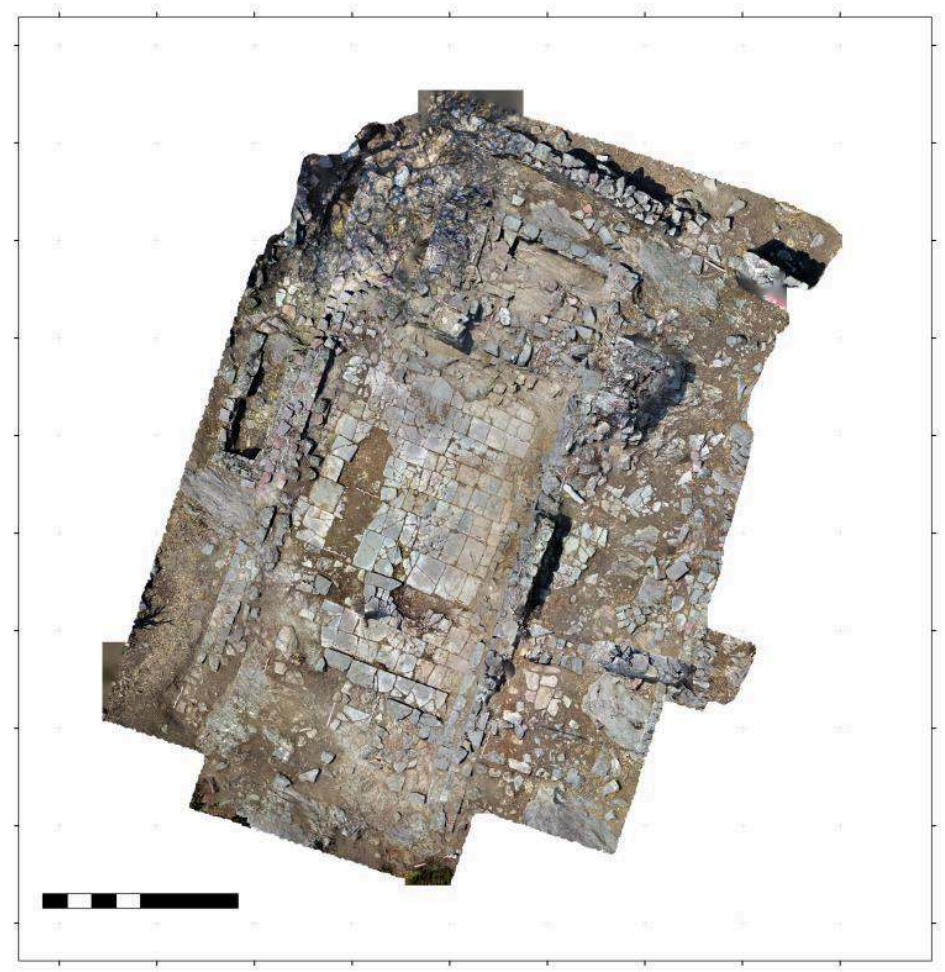

M. Ferrari.

Fig. 3 - Ortho-image du mur interne de la porte.

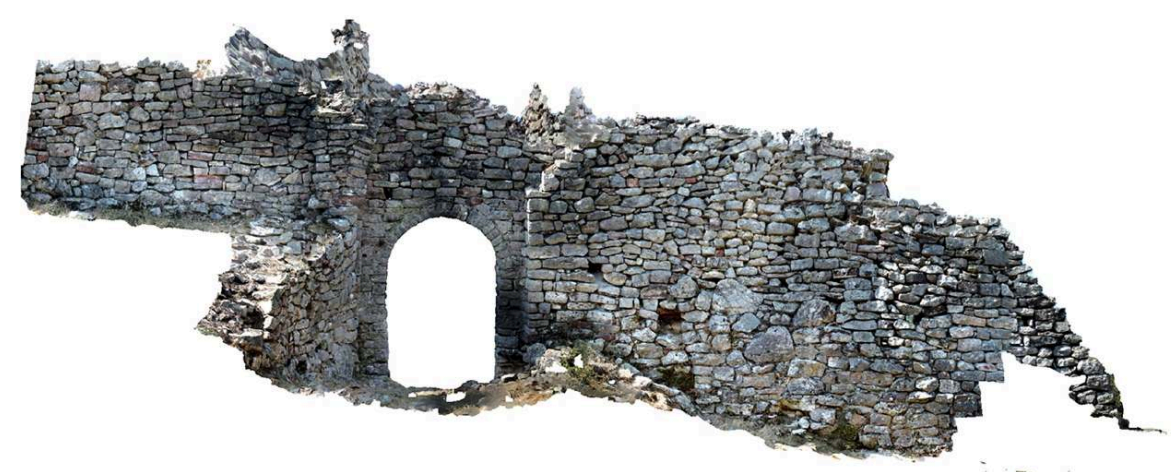




\section{Fouille de l'église du haut}

Dès la brève campagne de 2016 sur le site, un intérêt particulier a été porté sur la partie sommitale de la ville, ignorée par les fouilles anciennes. L'église identifiée à cet endroit a été débroussaillée une première fois en 2016, et a nécessité de nouveaux longs travaux de défrichement en 2017 (fig. 4). Une partie des blocs de construction recouvrant les espaces intérieurs et extérieurs ont été dégagés pour découvrir précisément les limites de l'édifice. Après compréhension du plan, l'opération a été orientée sur l'ouverture d'un grand sondage découvrant une partie occidentale de l'église.

Fig. 4 - États de dégagement de l'église entre le démarrage de la mission (à gauche) et la fin de la mission (à droite).

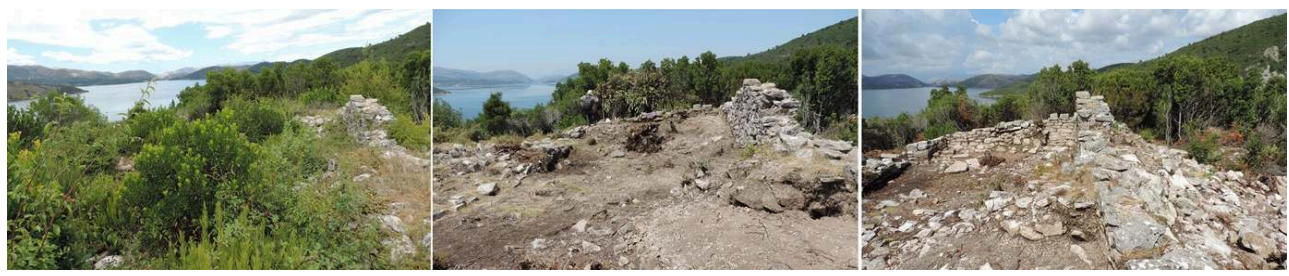

Cl. V. Gallien

7 Le nettoyage a révélé un bâtiment effondré sur lui-même. Il en subsiste un plan complet avec des élévations conservées sur $0,50 \mathrm{~m}$ à $2,00 \mathrm{~m}$ de hauteur (pour une portion de mur septentrional). L'intérieur de l'édifice était principalement comblé par des éléments de construction (blocs, dalles de calcaires et mortier blanc). Des pans de murs sont tombés de part et d'autre du bâtiment. La destruction est comprise comme le résultat d'une dégradation naturelle après abandon, sans destruction volontaire visible. La seule récupération de matériaux mise en évidence est celle du seuil de la porte d'entrée sud (voir ci-après). La position topographique de l'édifice dans la cité, rendant son accès peu pratique, a pu décourager les tentatives de démantèlement du bâtiment.

L'église est située au sommet de la colline, à 127, 588 m NGF. Elle a été installée sur le tracé du mur nord de l'enceinte intérieure, dite de la ville haute. Son mur septentrional se substitue au mur de clôture qui s'interrompt à quelques mètres de part et d'autre de l'édifice, d'une façon similaire à l'église dite "de la Vierge ", à l'autre extrémité de la même enceinte. Il est actuellement impossible de préciser si les deux constructions, donc l'église et l'enceinte sommitales, sont contemporaines ou successives.

9 À l'ouest de l'édifice, entre le mur de clôture et l'église, un accès (un porche ?) de 2,10 m de large a été obturé par une rangée d'épaisses dalles de calcaire longilignes, de 0,40 à $0,70 \mathrm{~m}$ de long pour $0,25 \mathrm{~m}$ de large (fig. 5). Cette ouverture dans le mur d'enceinte pourrait avoir desservi un passage ménagé le long de l'église. Un état final de la chaussée a été observé. Côté sud, des pierres posées maladroitement à plat évoquent une réparation de chaussée. Côté nord, un niveau de sol induré, composé de terre argileuse rouge, peut être attribué à une zone de circulation piétinée. Le côté ouest de ce sol semble délimité par un alignement de pierres sur chant dont le départ prend appui contre le mur. Cette possible bordure de chemin n'ayant pas été dégagée, on ne peut préciser son ancienneté. À l'opposé, sur l'angle nord-est de l'édifice, un important empierrement obstrue la lecture des niveaux et des relations entre l'église et la reprise 
du mur de clôture (fig. 6). Le tracé de ce dernier a été repéré à environ 5,00 $\mathrm{m}$ de l'église. Le mur prend une direction sud et rejoint la falaise. L'importance de l'empierrement conservé contre l'angle nord-est de l'église pourrait provenir de l'effondrement d'une construction telle qu'un second porche qui pourrait faire pendant à celui présumé à l'ouest. Ainsi deux portes pourraient avoir été ménagées de part et d'autre de l'église dans la clôture.

Fig. 5 - Sarda. Aménagement probable d'une porte extérieure entre l'angle nord-ouest de l'église $(A)$ et le mur de clôture $(E)$.

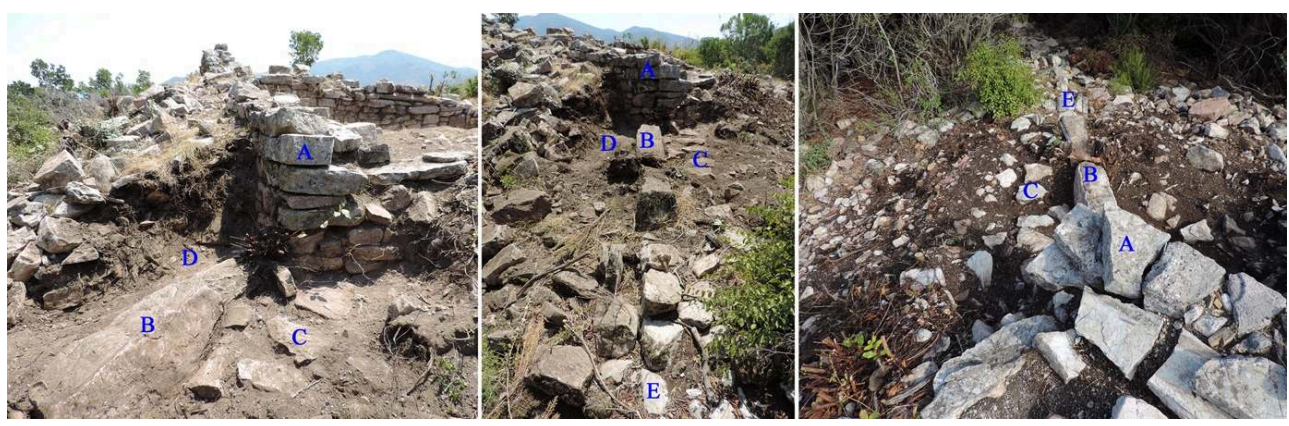

Dans son état final, la porte aurait été bouchée (B). Deux niveaux de sol, l'un grossièrement dallé (C), l'autre en terre battue (D) ont été repérés de chaque côté de cet accès.

Cl. V. Gallien.

Fig. 6 - Aménagement présumé de porte extérieure sous l'amas de pierre (B), entre l'arrière de l'abside de l'église (A) et le mur de clôture (C).

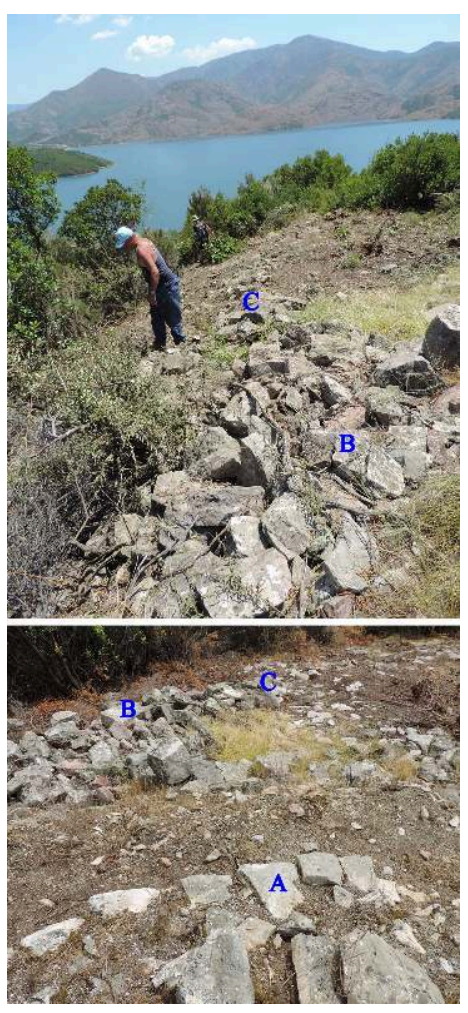

Cl. V. Gallien 


\section{Le plan de l'église (fig. 7-8)}

Fig. 7 - Photogrammétrie de l'église.

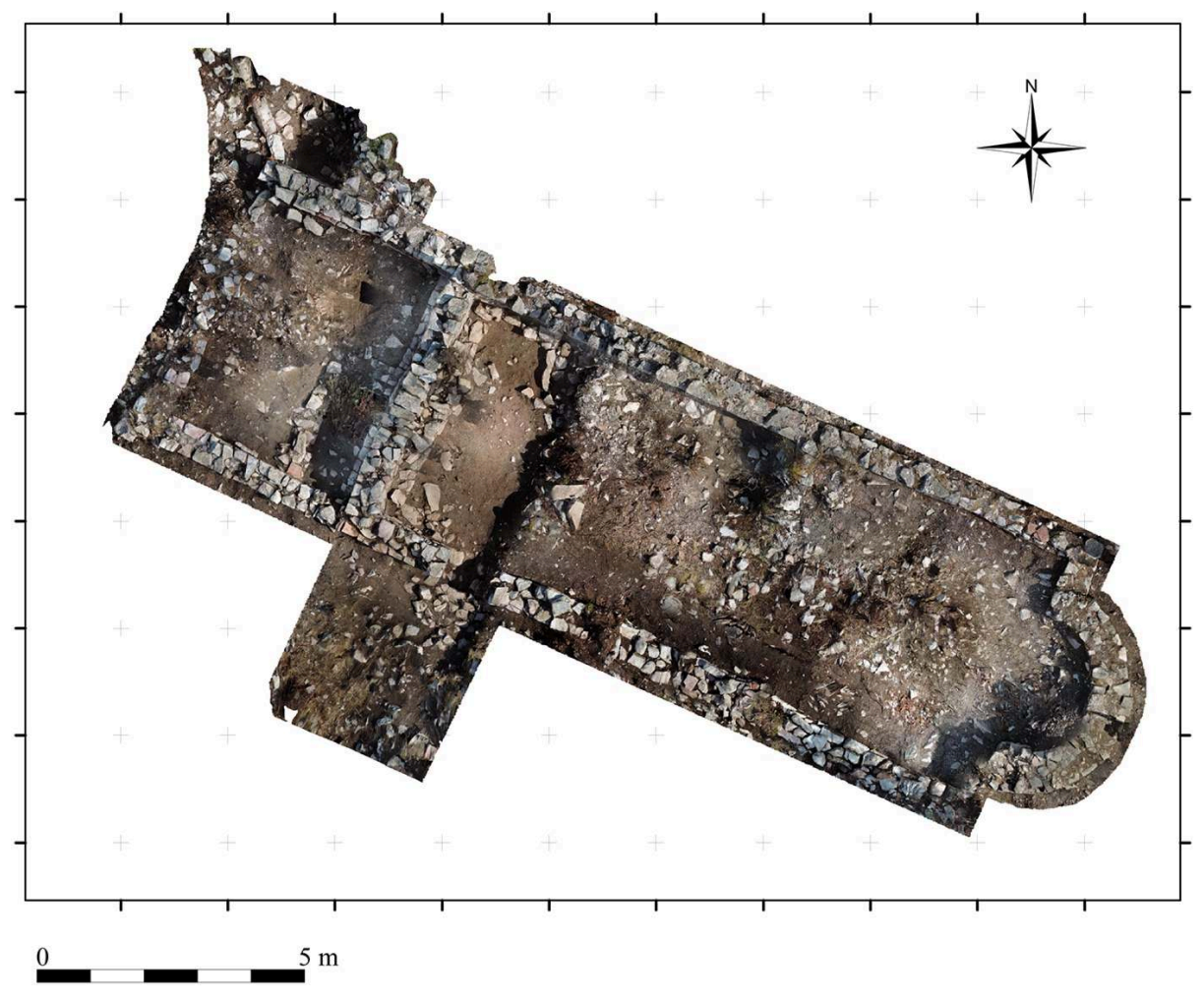

M. Ferrari. 
Fig. 8 - Plan de l'église et de son environnement.

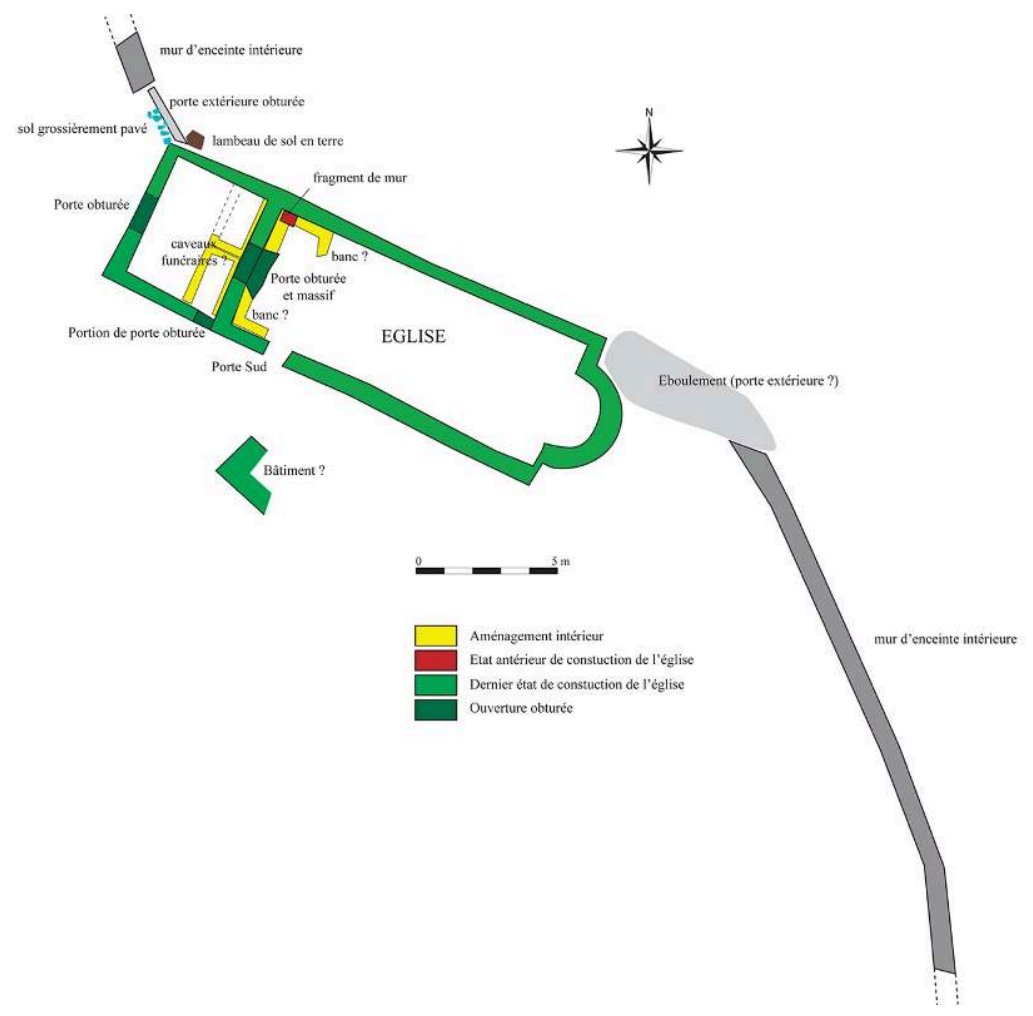

Relevé topographique M. Ferrari, DAO V. Gallien.

10 Dans sa phase finale, le bâtiment est une construction qui mesure extérieurement $19,50 \times 5,70 \mathrm{~m}$. Les murs font en moyenne 0,55 à $0,60 \mathrm{~m}$ d'épaisseur, jusqu'à $0,80 \mathrm{~m}$ pour l'abside. Ils sont montés avec de gros blocs décimétriques de calcaire liés au mortier.

11 Le plan se décompose en deux parties. La principale est une nef rectangulaire unique $(12,20 \times 4,50 \mathrm{~m}$ intérieur) terminée à l'est par une abside semi-circulaire saillante de 2,50 m d'ouverture pour 1,40 m de profondeur (fig. 9). L'abside parait excentrée : elle commence à $1,10 \mathrm{~m}$ du mur nord et à $0,90 \mathrm{~m}$ du mur sud de la nef. Cependant, cette observation demande à être vérifiée ultérieurement par la fouille de l'abside car la construction est endommagée sur le côté méridional. À l'ouest de la nef, une pièce rectangulaire $(3,50 \times 4,60 \mathrm{~m}$ intérieur) a probablement tenu lieu de narthex. 
Fig. 9 - Vues de l'abside orientale.

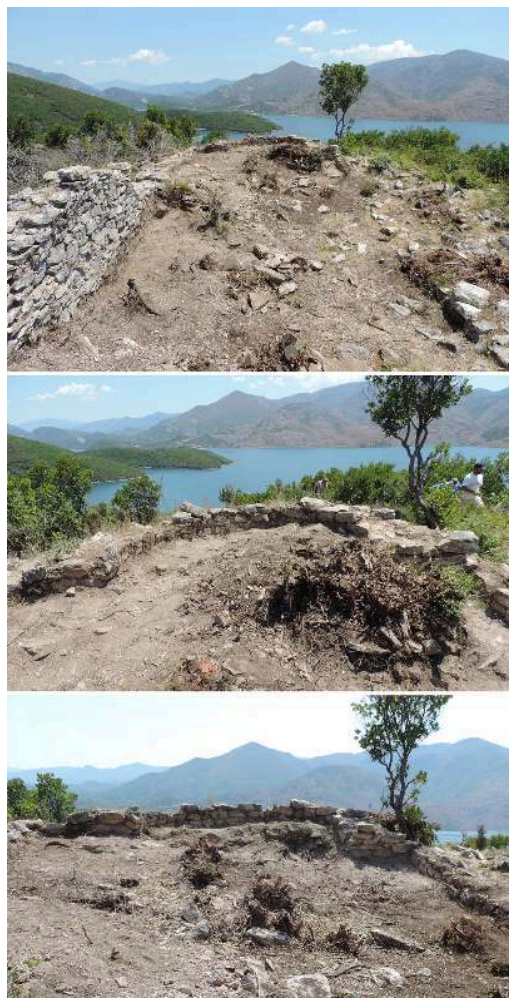

Cl. V. Gallien

12 Des ouvertures extérieures et intérieures ont été repérées. La première ouverture extérieure est une porte méridionale, aménagée à l'extrémité occidentale du mur sud de la nef (fig. 10). L'ouverture mesure $0,80 \mathrm{~m}$ de large. Le seuil a été partiellement récupéré, arrachant l'angle extérieur sud-est du mur. Il en reste seulement deux blocs chaînés aux pieds droits de la porte, du côté intérieur (fig. 11). Du côté intérieur, les investigations se sont arrêtées sur un sol d'argile rouge mêlée à des fragments de mortier (dernière occupation de l'église? sol d'abandon?). Vers l'extérieur, la porte donne sur un sol dallé de calcaire dont la première rangée a été découverte sous les blocs effondrés. 
Fig. 10 - La porte méridionale de l'église.

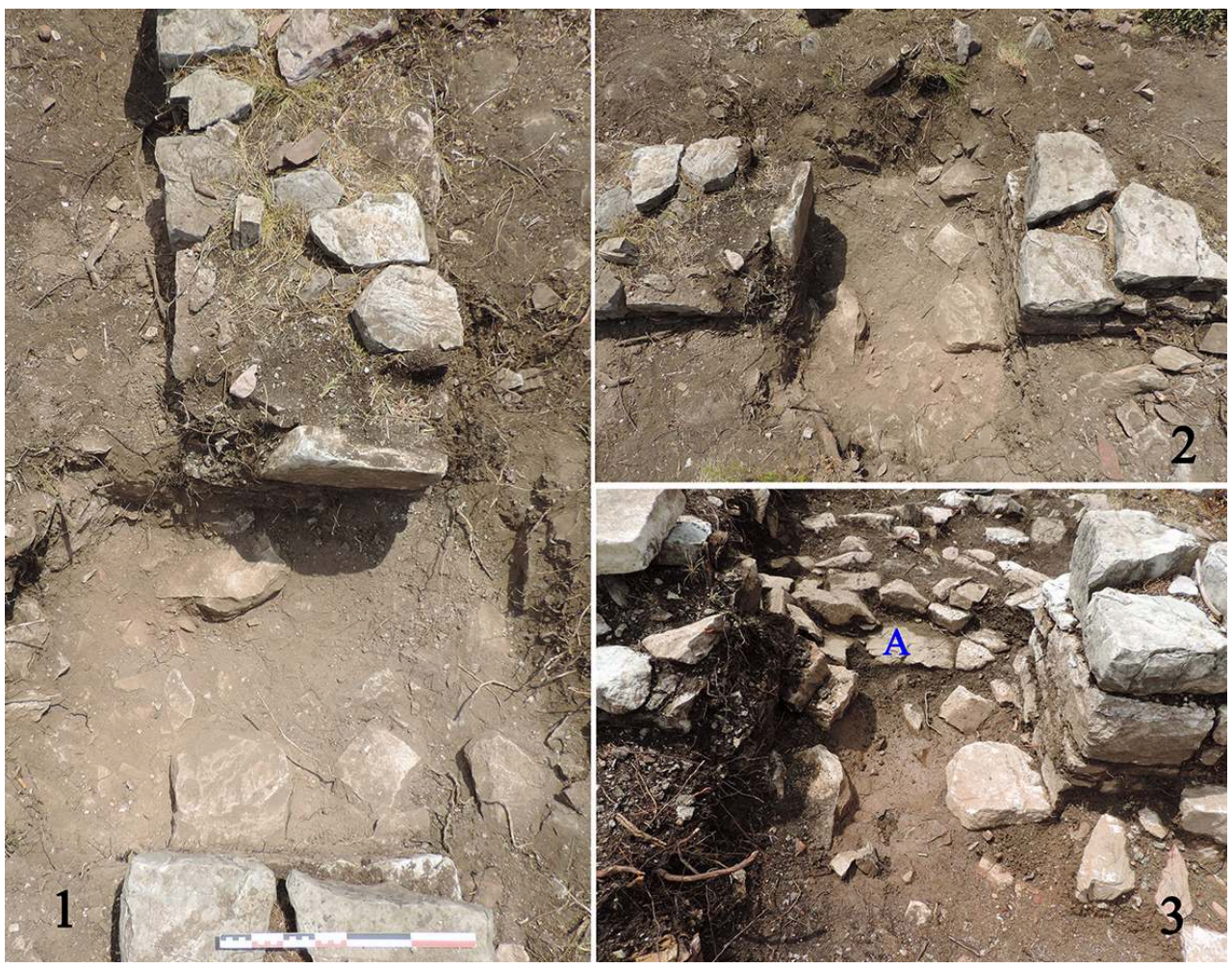

Vue de dessus (1) et depuis l'intérieur de l'église (2-3), avec les restes d'un sol dallé extérieur (A). Cl. V. Gallien. 
Fig. 11 - Arrachage du seuil de la porte méridionale.

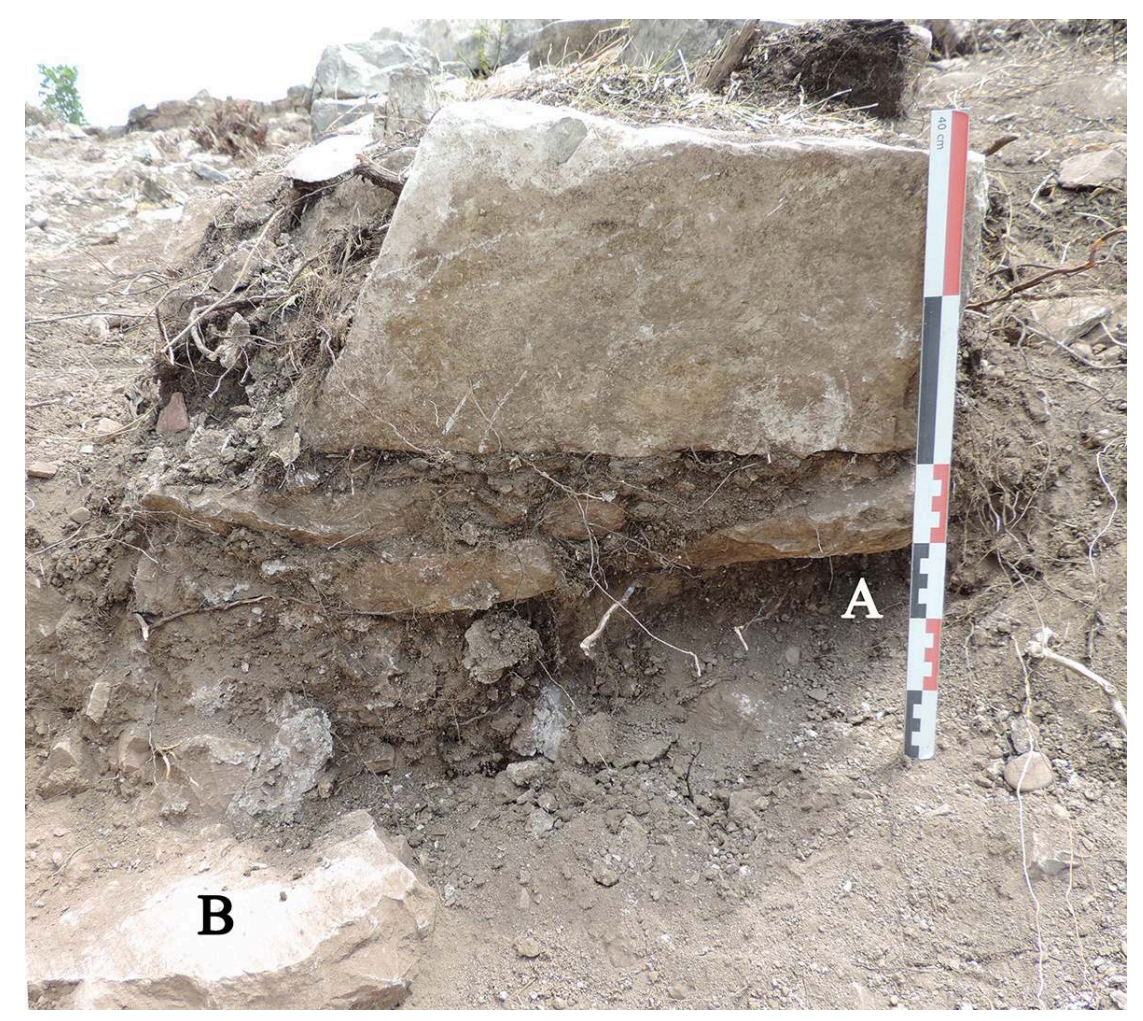

Les traces d'arrachage sont repérables à partir de la sape (A) observée dans la construction du piédroit oriental. Le niveau de circulation devait se présenter à la hauteur du bloc $\mathrm{B}$ (élément de sol ?).

Cl. V. Gallien.

13 Une ouverture intérieure de 1,45 $\mathrm{m}$ de large a été observée dans le mur ouest de séparation entre la nef et le narthex (fig. 12). Comme l'abside, elle est excentrée avec le même décalage de $0,20 \mathrm{~cm}$ entre les murs nord et sud. La porte a été ultérieurement bouchée avec un gros massif de pierres qui déborde du mur du côté de la nef (fig. 13 et 17). En l'état des investigations, il est difficile de préciser le rôle de ce massif encadré de longs blocs disposés perpendiculairement à l'entrée : contrefortement de l'entrée obturée ? base d'une installation liturgique (autel ?) ou funéraire (tombeau ?). Lié à ce massif, un aménagement empierré de faible hauteur $(0,37$ à $0,40 \mathrm{~m})$ double le mur occidental. Cette construction basse évoque les restes d'un banc. 
Fig. 12 - Porte d'accès de la nef au narthex obturée. Vue depuis la nef vers l'ouest (A) et vue depuis le narthex vers l'est (B).

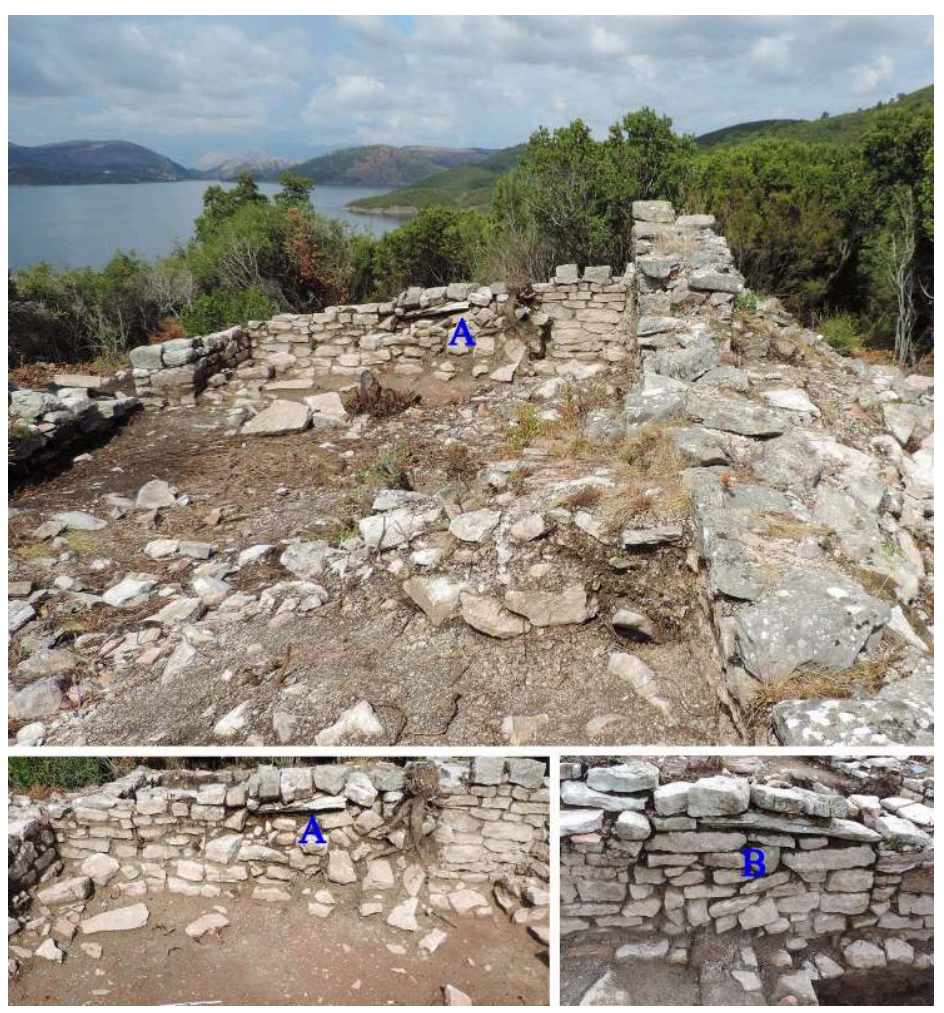

Cl. V. Gallien 
Fig. 13 - Aménagement du mur occidental de la nef.

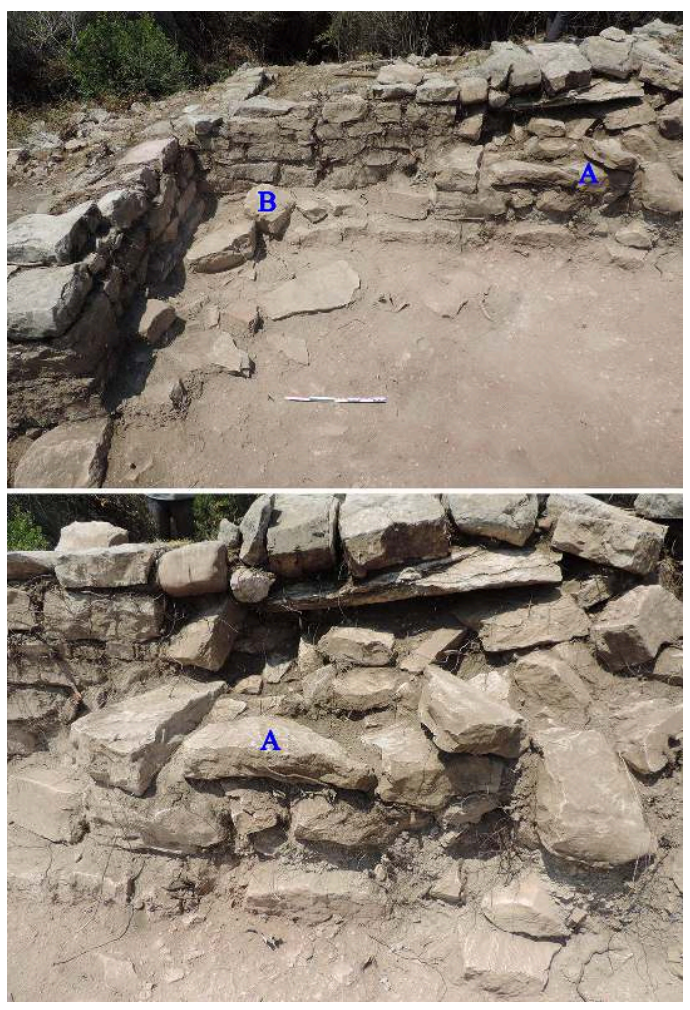

Un massif colmate la porte entre nef et narthex (A) et à un aménagement doublant le mur occidental de la nef, pourrait correspondre à un banc (B).

Cl. V. Gallien.

14 Il semble qu'une ouverture dans le mur extérieur ouest fasse pendant à la porte intérieure, seul le côté sud est repéré (fig. 14). L'état du dégagement à l'avant de l'église n'a pas permis d'identifier correctement cette ouverture. 
Fig. 14 - Présomption de porte d'entrée occidentale dont le piédroit sud (A) semble avoir été repéré.

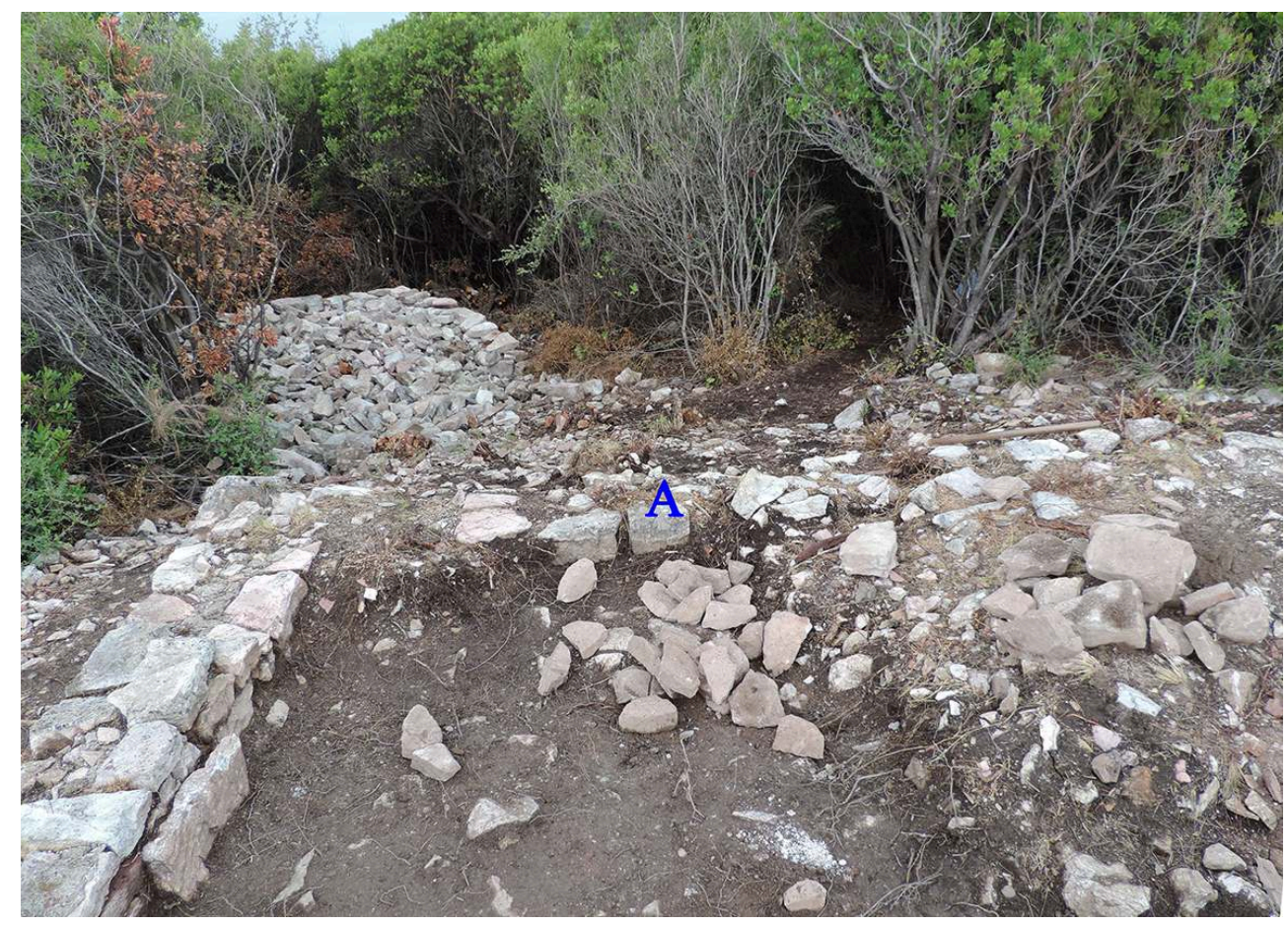

Cl. V. Gallien.

15 Une dernière porte a été repérée dans le mur sud du narthex, à l'extrémité orientale, contre le mur de la nef. L'espace entre le pied droit ouest parementé de la porte et le mur de séparation narthex-nef, mesure à peine $0,60 \mathrm{~m}$ de large et donne une ouverture trop étroite pour une porte sauf à considérer qu'il s'agit d'une ancienne ouverture appartenant à un plan antérieur de l'édifice (fig. 15). 
Fig. 15 - Possible ouverture dans le mur sud du narthex (A), près du mur de séparation nef/ narthex.
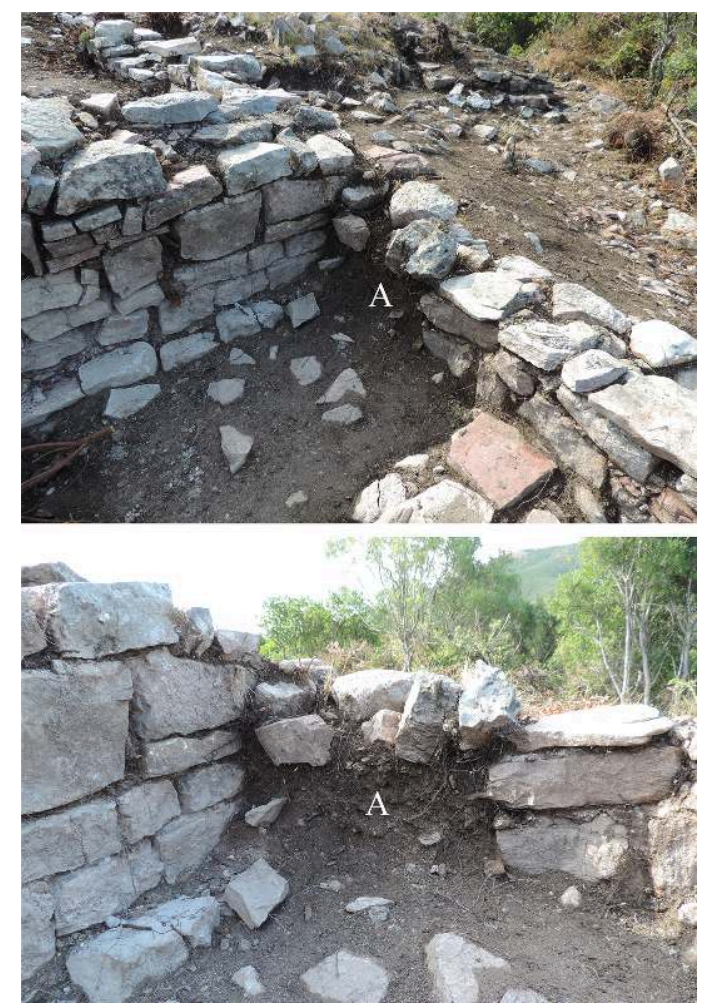

Cl. V. Gallien.

Le large sondage effectué dans la nef a précisément permis de repérer deux états de constructions (fig. 16). L'élévation du mur nord présente, à $0,60 \mathrm{~m}$ de son angle nordest, un coup de sabre (limite entre les murs $1 \mathrm{~A}$ et $2 \mathrm{~A}$ ). Au pied de ce coup de sabre un massif de maçonnerie arasé (mur 1B) est chaîné à la portion ouest du mur nord (mur 1A) et forme un angle (ancienne limite de la nef?). La reprise du mur nord (mur 2A) est, quant à elle, chaînée avec le mur de séparation nef-narthex (mur 2B) repoussé de $0,15 \mathrm{~m}$ vers l'ouest par rapport au mur $1 \mathrm{~B}$. Nous avons clairement deux états de construction de l'église avec deux angles emboîtés. La reprise (murs 2A et 2B) semble correspondre à agrandissement d'une première nef (murs 1A et 1B). 
Fig. 16 - Vues de l'angle nord-ouest de la nef avec une reprise de maçonneries.

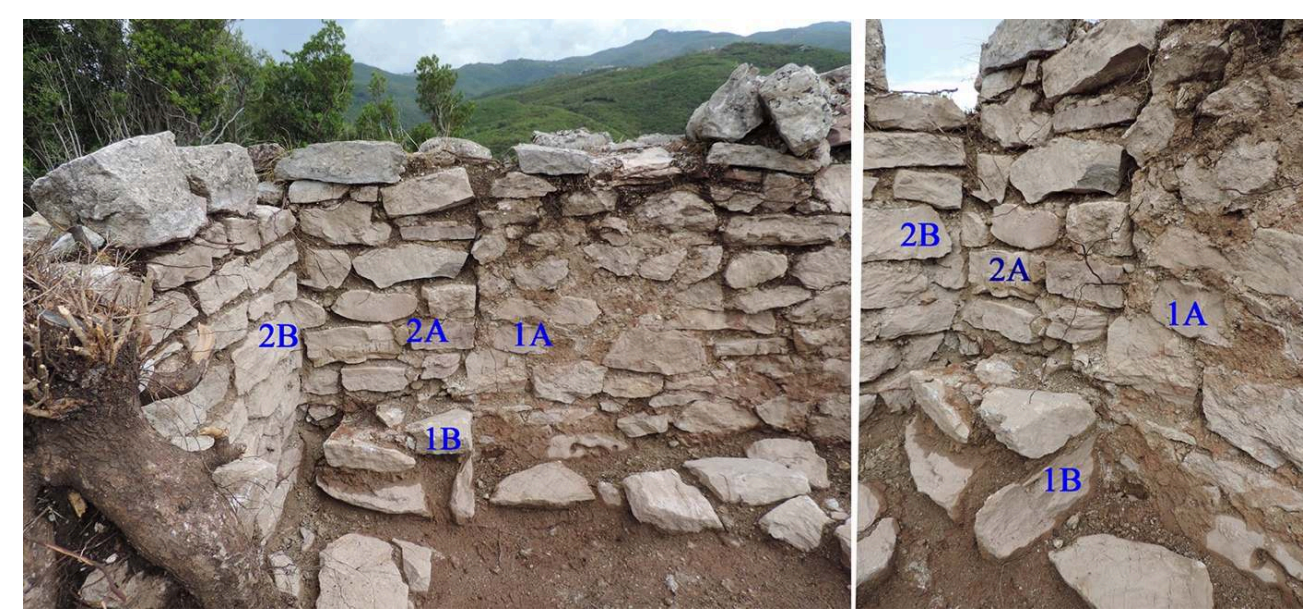

On repère un coup de sabre entre la portion de mur 1A et la portion plus récente de mur 2A. Cette dernière recouvre la partie arasée du mur 1B qui est chaîné au mur 1A. Le mur 1B semble correspondre à un retour sud du mur 1A. Tandis que le mur de séparation nef/narthex (2B) est associé et chaîné au mur plus récent $2 A$.

Cl. V. Gallien.

\section{Les aménagements intérieurs}

Dans la partie occidentale de la nef dégagée par le sondage, un banc aménagé contre les murs semble pouvoir être restitué (fig. 17) ; son existence devra être confirmée lors des opérations de fouille ultérieures. Il est présupposé à partir d'un massif de 0,37 à $0,40 \mathrm{~m}$ de large qui double le mur intérieur de l'église, côté nef. Il englobe, notamment, l'arase du mur 3, conservé sur environ $0,40 \mathrm{~m}$ de long. On note que l'aménagement s'interrompt au niveau de la porte intérieure ouest et de l'épais massif aménagé contre le bouchage de la même porte. 
Fig. 17 - Possible banc le long du mur occidental.

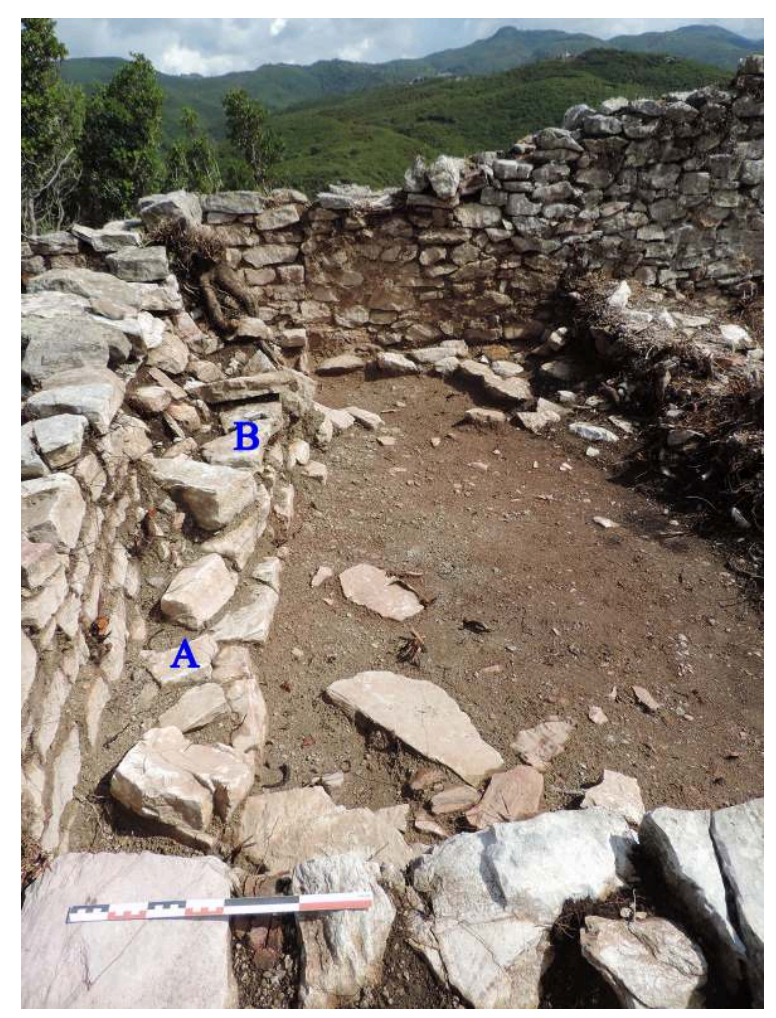

Un banc (A) a vraisemblablement été aménagé à partir de l'arasement d'un mur conservé le long du mur occidental de la nef (ici vu vers le nord), il est associé au massif obturant le passage entre la nef et le narthex (B).

Cl. V. Gallien.

Dans le narthex, le sondage a permis de mettre en évidence des maçonneries liées au mortier de 0,35 à $0,50 \mathrm{~m}$ de large dont certaines étaient accolées au mur de séparation nef-narthex (fig. 18). Elles ont été interprétées comme des parois de caveaux funéraires à partir du plan rectangulaire de 2,30 × 1,45 extérieur (pour un espace intérieur de $2,00 \times 0,90 \mathrm{~m}$ ) qu'elles présentaient (fig. 19). L'identification a été complétée grâce aux deux fragments osseux humains (temporal et calcanéum) découverts dans le comblement supérieur de la structure avec plusieurs éléments de faune. Un sondage de $0,80 \mathrm{~m}$ de côté effectué sur 0,50 m de profondeur n'a pas permis d'observer de corps en place, mais s'est interrompu sur un niveau dallé qui pourrait correspondre à un niveau de couverture (fig. 20). Ses côtés nord et ouest sont accolés à d'autres maçonneries qui pourraient être celle de caveaux supplémentaires. En l'état des dégagements, l'ensemble apparaît lié et rappelle le groupe de caveaux funéraires découverts dans l'église de la citadelle de Lezha (fouilles 2013 et 2014). Les campagnes de fouille suivante devront établir les relations entre les maçonneries et les différents états de construction de l'église et vérifier si leur construction pourrait faire partie d'un programme architectural de l'édifice. Sans surprise, il est possible de préciser que les murs étaient enduits et peints. Des fragments contenant des traces de couleur jaune, rouge et bleue ont été observés. 
Fig. 18 - Caveaux funéraires dans le narthex ?

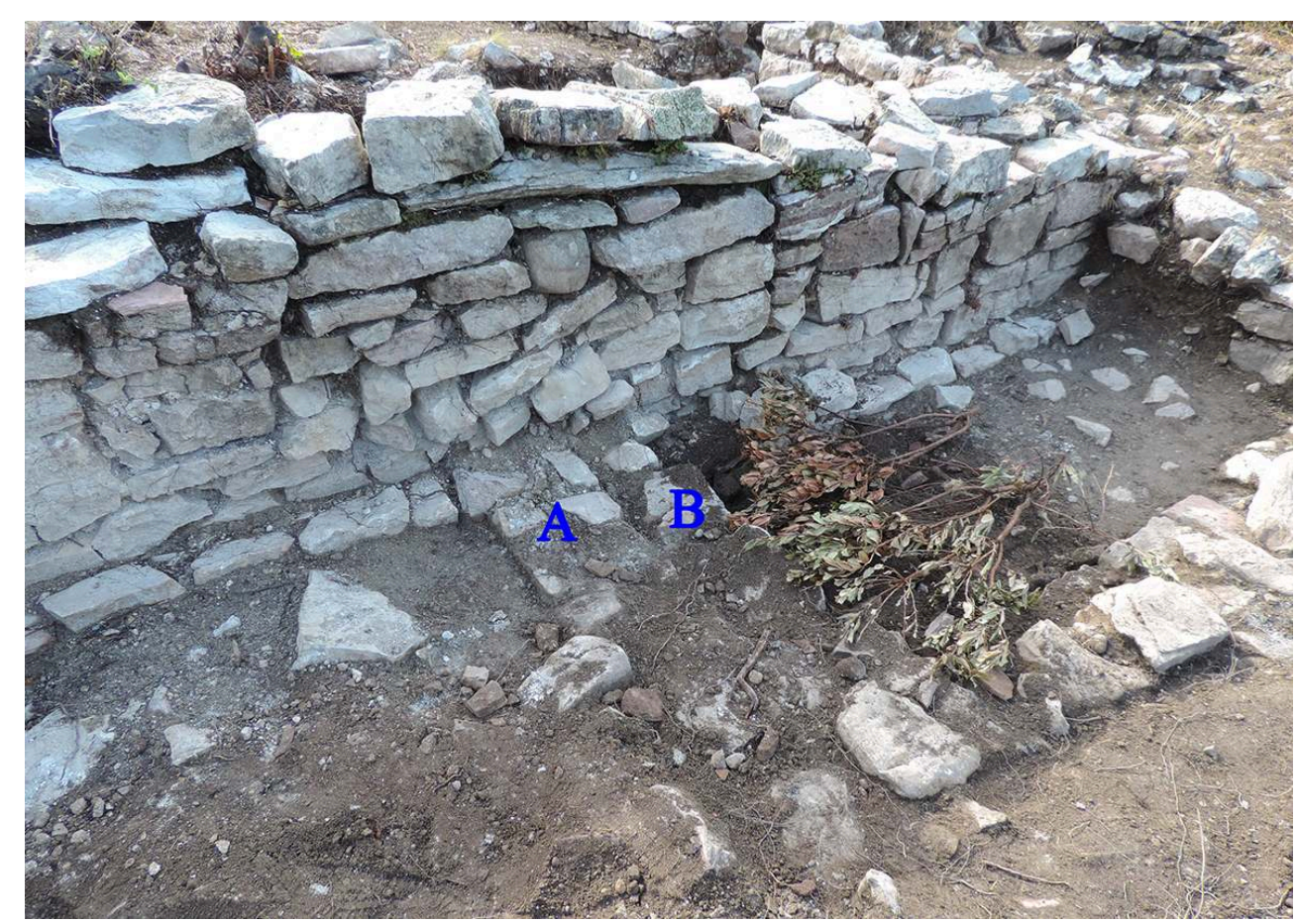

Deux maçonneries (A et B) dans le narthex, en avant du passage menant à la nef, sont interprétés comme des éléments de caveaux funéraires.

Cl. V. Gallien. 
Fig. 19 - Caveau funéraire dans le narthex ?
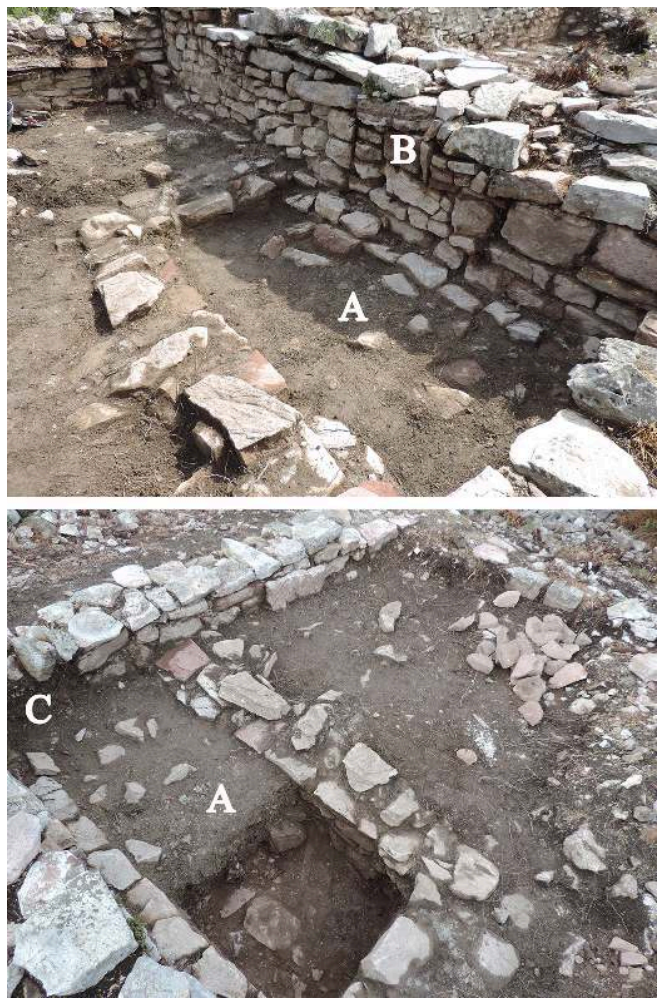

Autres vues vers le nord (cliché du haut) et vers le sud (cliché du bas) du probable caveau funéraire (A) aménagé en avant du passage obturé entre le narthex entre la porte occidentale (B) et contre l'ouverture bouchée dans le mur sud du narthex (C).

Cl. V. Gallien. 
Fig. 20 - Caveau funéraire dans le narthex.

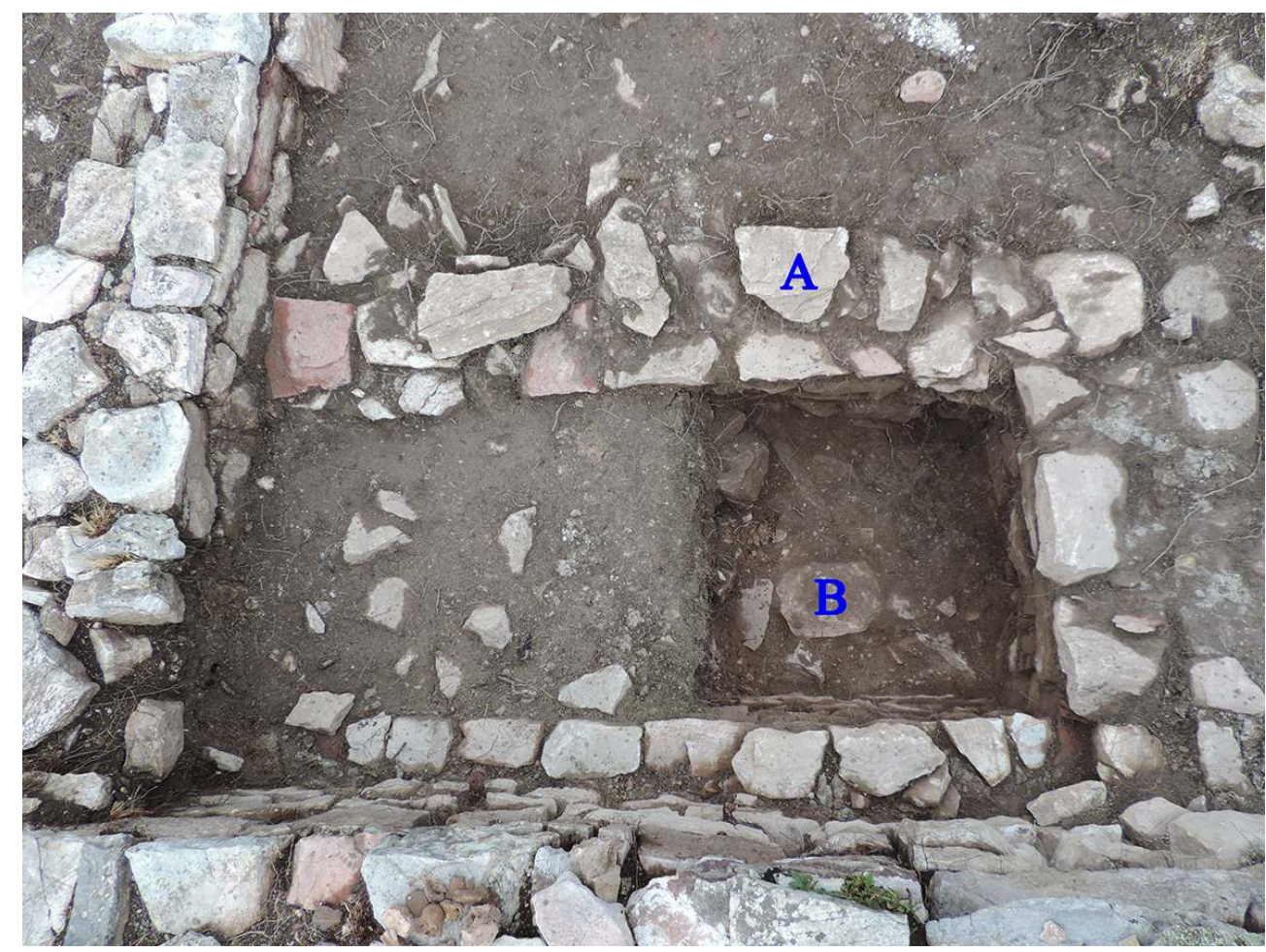

Un sondage (B) dans un probable caveau (A) dans l'angle sud-est du narthex a été interrompu à l'apparition d'un niveau dallé, possible couverture d'une sépulture.

Cl. V. Gallien.

En dehors des quelques ossements extraits du comblement du caveau installé dans le narthex et de quelques fragments d'enduits peints recueillis dans les niveaux de démolition, aucun artéfact n'a été relevé, en particulier aucun élément mobilier datant. Il est donc actuellement impossible de dater précisément d'édifice à l'intérieur de la période médiévale.

\section{Les constructions extérieures}

Lors de la campagne d'intervention de 2016, un mur était apparu du côté sud-est de l'église. Cette année, un angle de mur a été dégagé à $2,50 \mathrm{~m}$ de la porte méridionale de la nef (fig. 21). Il indique la présence de bâtiments proches de l'église sur son côté sud. Un actuel important empierrement de ce côté de l'église ne dément pas ces observations. En revanche, du côté nord, les pierres observées dans la pente semblent davantage provenir de l'effondrement du mur nord de la nef ainsi que probablement de la couverture de l'église. 
Fig. 21 - En avant de la porte méridionale (A), repérage d'un angle de mur de bâtiment (B).

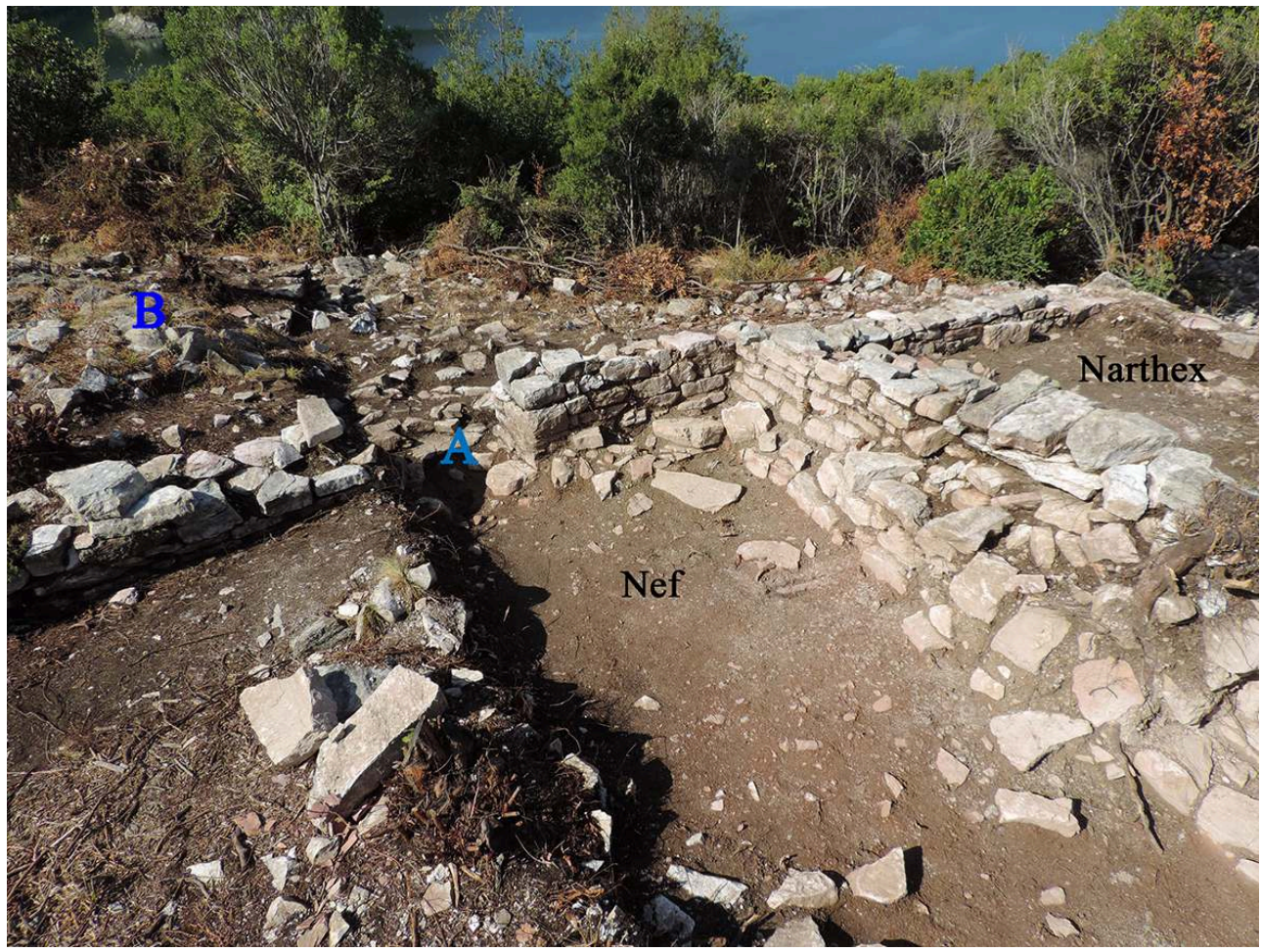

Cl. V. Gallien

\section{Conclusion et perspectives}

Cette campagne d'intervention sur l'île de Sarda a permis, tout d'abord de réaliser la topographie et l'enregistrement photogrammétrique d'une partie des monuments de la ville ; de corriger le plan de l'église inséré dans un complexe de bâtiments, située à l'est de la ville basse ; de dégager le dernier plan de l'église sommitale de la ville haute. Le grand sondage engagé dans ce monument a montré d'une part l'existence de plusieurs états de construction et d'autre part l'utilisation funéraire de l'édifice.

Les campagnes archéologiques ultérieures sur cet édifice devront porter sur le dégagement intérieur et s'intéresser en particulier à l'occupation funéraire du narthex, aux aménagements intérieurs (bancs, sols) et aux installations liturgiques de l'abside, qui devrait être, avec un peu de chance, en partie conservées.

23 Conjointement à la fouille de l'église même, il conviendra d'étendre les recherches aux constructions jouxtant l'édifice religieux sur son côté méridional, pour commencer à appréhender l'organisation du quartier, le rapport chronologique entre l'église et la clôture nord de l'enceinte sommitale ainsi que vérifier la poursuite vers le sud de cette enceinte qui représenterait un quartier clos. 


\section{NOTES}

1. Trois campagnes de fouilles ont été menées préalablement à l'immersion imminente d'une partie du site, lors de la construction du barrage dans les années 1970. Quelques sépultures du cimetière situé au pied de la colline, actuellement sous les eaux du Drin, ont aussi été fouillées, ainsi qu'une portion de l'église funéraire, voir D. Komata, Gjurmime në varrezën e Shurdhahut (Sondages dans le cimetière de Shurdhah), dans Studime Historike, 1, 1967, p. 127-142 ; H. Spahiu, D. Komata, Shurdhah - Sarda, qytet mesjetar shqiptar i fortifikuar: Rezultatet e gërmimeve 1967-1970 (Sarda, ville médiévale albanaise fortifiée : les résultats des fouilles 1967-1970), dans Iliria, 3, 1974, p. 257-328 ; et H. Spahiu, Qyteti shqiptar mesjetar i hershem i Shurdhahut (La ville haute médiévale albanaise de Shurdhah, Sarda) dans Iliria, 5, 1976, p. 151-167. De solides travaux de restauration ont été menés par l'Institut des Monuments historiques de Tirana. Ils ont été concentrés sur des portions des deux enceintes et de la porte de la ville haute, ainsi que sur une des églises de la même ville, voir Gj. Karaiskaj, Të dhëna mbi arkitekturën dhe punimet e konservimit në kalanë e Shurdhahut (Sarda) (Données sur l'architecture de la forteresse de Shurdhah [Sarda] et sur les travaux de restauration qui y ont été effectués), dans Monumentet, 10, 1975, p. 133-150. À cette occasion, l'auteur a proposé une chronologie de la fondation de la ville ainsi que de certains bâtiments ecclésiastiques de la ville basse.

2. Les premiers relevés ont été engagés sur l'enceinte haute et sur un complexe, dans la ville basse, composé d'une église entourée de bâtiments à vocation supposée domestique. La couverture photo géoréférencée a été prêtée par P. Pilz, de la mission archéologique albanopolonaise de Shkodra.

3. Voir Gj. Karaiskaj, Qyteti shqiptar i Sardës. Origjina dhe zhvillimi $i$ qytetit mesjetar në Shqipërinë e Veriut (La ville albanaise de Sarda. L'origine et l'évolution de la ville médiévale en Albanie du nord), dans Monumentet, 1, 1987, p. 73-85.

4. K. Jireček, Skutari und sein Gebiet im Mittelalter, dans L. von Thallóczy (dir.), Illyrisch-Albanische Forschungen, Munich-Leipzig, 1916, vol. 1, p. 116.

\section{INDEX}

Mots-clés : Albanie, Adriatique, évêché latin de Sarda, église, photogrammétrie, vallée de Drin, archéologie du bâti

institutions Ministère de l'Europe et des Affaires étrangères (Paris), École française de Rome, Labex RESMED (Paris), Institut d'Archéologie de Tirana (Académie des études albanaises Tirana), UMR 8167 « Orient et Méditerranée » (Monde byzantin - Paris), UMR 7264

«CEPAM » (Nice)

\section{AUTEURS}

\section{ETLEVA NALLBANI}

CNRS, UMR 8167/Orient et Méditerranée, Paris - etleva.nallbani@college-de-france.fr 


\section{VÉRONIQUE GALLIEN}

INRAP - veronique.gallien[at]inrap.fr

\section{HELIDON SOKOLI}

Directorat régional de la culture nationale de Shkodra - helidon_sokoli1980@yahoo.it 